Document downloaded from:

http://hdl.handle.net/10251/171688

This paper must be cited as:

Vallés-García, C.; Gkaniatsou, E.; Santiago-Portillo, A.; Giménez-Marqués, M.; Alvaro Rodríguez, MM.; Greneche, J.; Steunou, N.... (2020). Design of stable mixed-metal MIL$101(\mathrm{Cr} / \mathrm{Fe})$ materials with enhanced catalytic activity for the Prins reaction. Journal of Materials Chemistry A. 8(33):17002-17011. https://doi.org/10.1039/d0ta02991b

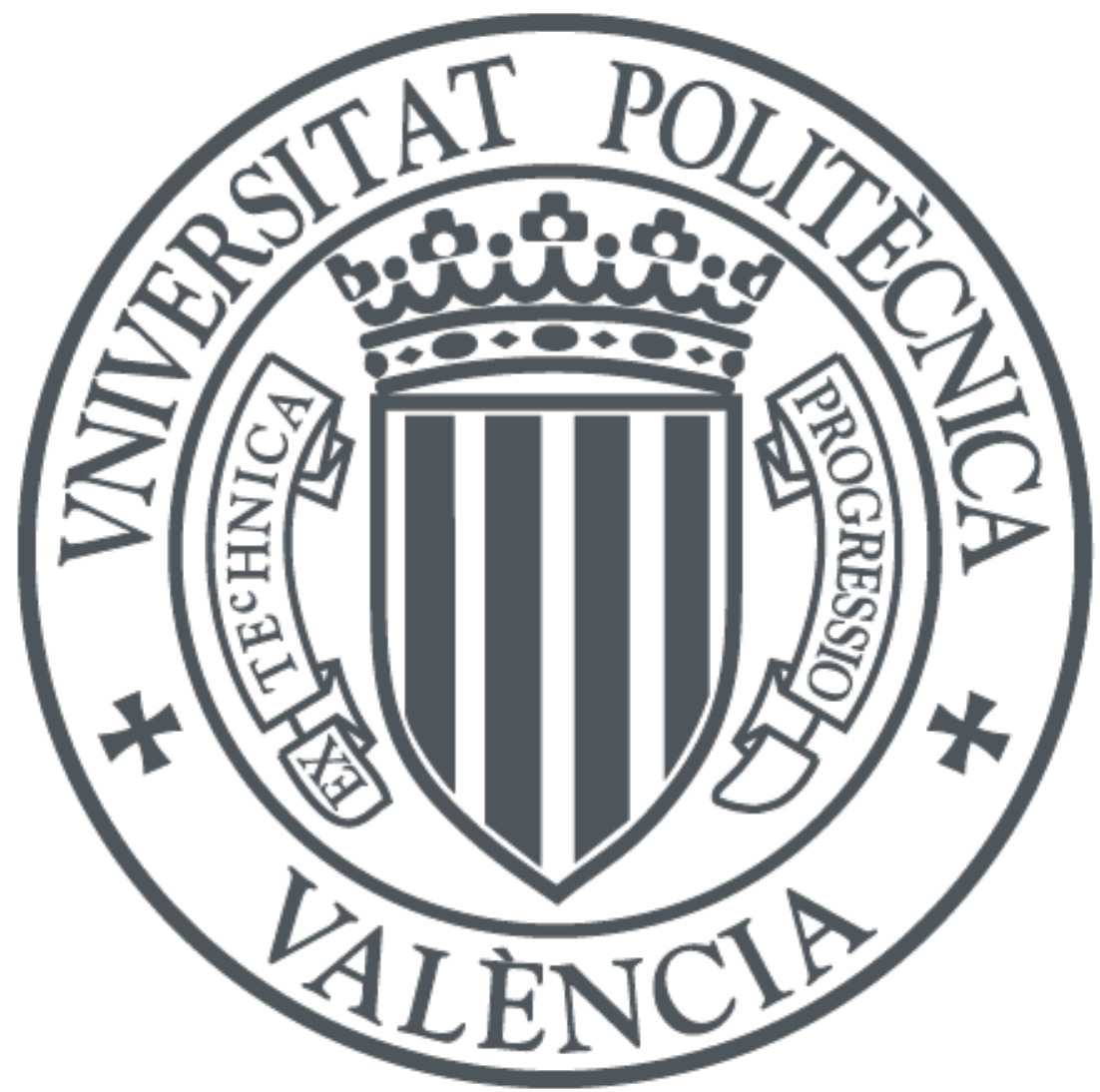

The final publication is available at

https://doi.org/10.1039/d0ta02991b

Copyright The Royal Society of Chemistry

Additional Information 


\title{
Design of stable mixed-metal MIL-101(Fe/Cr) materials with enhanced catalytic activity for the Prins reaction
}

\begin{abstract}
Cristina Vallés-García, ${ }^{a, \$}$ Effrosyni Gkaniatsou, ${ }^{b, \$}$ Andrea Santiago-Portillo, ${ }^{a}$ Mónica GiménezMarqués, ${ }^{c}$ Mercedes Álvaro, ${ }^{a}$ Jean-Marc Greneche, ${ }^{d}$ Nathalie Steunou, ${ }^{b}$ Clémence Sicard, ${ }^{b,}{ }^{*}$ Sergio Navalón, ${ }^{a, *}$ Christian Serre, ${ }^{d, *}$ Hermenegildo García ${ }^{\text {f, }}{ }^{*}$

This work highlights the benefit of designing mixed-metal $(\mathrm{Cr} / \mathrm{Fe})$ MOFs for enhanced chemical stability and catalytic activity. A robust and stable mixed-metal MIL-101 $(\mathrm{Cr} / \mathrm{Fe})$ was prepared through a HF-free direct hydrothermal route with $\mathrm{Fe}^{3+}$ content up to $21 \mathrm{wt} \%$. The incorporation of $\mathrm{Fe}^{3+}$ cations in the crystal structure was confirmed by ${ }^{57} \mathrm{Fe}$ Mössbauer spectrometry. The catalytic performance of the mixed metal MIL-101( $\mathrm{Cr} / \mathrm{Fe})$ was evaluated in the Prins reaction. MIL$101(\mathrm{Cr} / \mathrm{Fe})$ exhibited a higher catalytic activity compared to MIL-101(Cr), improved chemical stability compared to MIL$101(\mathrm{Fe})$ and a higher catalytic activity for bulky substrates compared to MIL-100(Fe). In situ infra-red spectroscopy study suggests that the incorporation of $\mathrm{Fe}^{3+}$ ions in MIL-101 structure leads to an increase in Lewis acid sites. It was thus concluded that the predominant role of $\mathrm{Cr}^{3+}$ ions was to maintain the crystal structure, while $\mathrm{Fe}^{3+}$ ions enhanced the catalytic activity.
\end{abstract}

\section{Introduction}

Metal-organic frameworks (MOFs) have been successfully applied as catalysts for a large variety of liquid-phase reactions. $^{1-5}$ Of particular importance are the Lewis acidcatalyzed processes due to the wide reaction range and their general applicability for the production of fine chemicals, pharmaceuticals and agrochemicals. ${ }^{6}$ Some examples have shown the superiority as catalysts of MOFs versus zeolites to promote Lewis acid-catalyzed reactions in the liquid phase. ${ }^{7,8}$

Among the most commonly used MOFs as heterogeneous catalysts, MIL-101(Cr) combines a series of desirable properties, including: i) an exceptional chemical and a suitable thermal stability, ii) a very high porosity with wide pentagonal $(1.2 \mathrm{~nm})$ and hexagonal $(1.4 \mathrm{~nm})$ windows to access to the

\footnotetext{
a. Departamento de Química, Universitat Politècnica de València, C/Camino de Vera, $s / n, 46022$ Valencia, Spain

${ }^{b}$. Institut Lavoisier de Versailles, UMR CNRS 8180, Université de Versailles SaintQuentin-en-Yvelines, Université Paris Saclay, France

Instituto de Ciencia Molecular (ICMol), Universidad de Valencia, C/Catedrático José Beltrán 2, Paterna 46980, Spain

d. Institut des Molécules et Matériaux du Mans, UMR CNRS 6283, Université du Maine, Le Mans, France

. Institut des Matériaux Poreux de Paris, UMR 8004 CNRS Ecole Normale Supérieure, Ecole Supérieure de Physique et de Chimie Industrielles de Paris, PSL university, Paris, France.

f. Instituto de Tecnología Química CSIC-UPV, Universitat Politècnica de València, Consejo Superior de Investigaciones Científicas, Av. de los Naranjos s/n, 46022 Valencia, Spain

g. Center of Excellence for Advanced Materials Research, King Abdulaziz University, Jeddah, Saudi Arabia

h.\$ Both are considered as first authors

Electronic Supplementary Information (ESI) available: [details of any supplementary information available should be included here]. See
} DOI: $10.1039 / x 0 x x 00000 x$ mesoporous cavities (2.9 and $3.4 \mathrm{~nm}$ in diameter), iii) a large surface area (3000-4200 $\left.\mathrm{m}^{2} \mathrm{~g}^{-1}\right)$, and iv) a tunable composition through organic ligand substitution and metal node modification. $^{9}$ Importantly, after the removal of water molecules coordinated to the metal sites, the metal node cluster $\left(\mathrm{Cr}^{3+}\right.$-trimer) presents inherent Lewis acidity. ${ }^{7}$ Thus, MIL-101(Cr) has been widely reported as heterogeneous catalyst for those reactions that require Lewis acid sites ${ }^{7,10}$ or redox ${ }^{11-13}$ centers.

Heterogeneous catalysis is continuously searching for more active and selective catalysts. In the particular case of MOFs as solid Lewis acids, this target can be achieved, by at least, two alternative ways, either by introducing electron-withdrawing substituents on the organic linker or by selecting metal ions with higher acid strength. In this context, it has been reported that the catalytic activity as Lewis acid of MIL-101(Cr) can be increased up to three orders of magnitude by introducing electron-withdrawing groups such as nitro groups in the organic ligand. ${ }^{10}$ However, a complementary strategy would be to partially replace $\mathrm{Cr}^{3+}$ by other appropriate transition metal. Regarding the possibility to enhance Lewis acidity by proper selection of the transition metal, an obvious choice is the replacement of $\mathrm{Cr}^{3+}$ by $\mathrm{Fe}^{3+}$ in MIL-101. It has been previously established that for some reactions MIL-101(Fe) is more efficient as catalyst than MIL-101(Cr), ${ }^{14}$ although the direct comparison between the catalytic activity of $\mathrm{Cr}^{3+}$ and $\mathrm{Fe}^{3+}$ is in most cases not possible due to the different nature of the accompanying counter anion, particles sizes and other parameters. In addition, MOFs bearing Lewis acid sites such as MIL-100 or MIL-101 often suffer from a partial poisoning of the most active metal sites by impurities (ligand, anion...). ${ }^{15}$ Thus 
depending on the activation conditions, the same material can exhibit a significantly different density of Lewis sites of different strength, ${ }^{16}$ making thus comparison between various samples cumbersome.

In this context, the lower chemical stability of MIL-101(Fe), easily converted upon exposure to water or polar organic solvents to the less porous MIL- $88 \mathrm{~B}(\mathrm{Fe}),{ }^{17}$ has hampered the determination of the real catalytic activity of $\mathrm{Fe}^{3+}$ ions in the MIL-101 structure in comparison with the $\mathrm{Cr}^{3+}$ analogue.

Previously, some of us have reported the direct preparation of mixed $\mathrm{Cr} / \mathrm{Fe} \mathrm{MIL}-53$ materials. It was shown that the introduction of $\mathrm{Cr}^{3+}$ ions into the Fe-MOF was accompanied by a strong enhancement of the chemical stability. ${ }^{18}$ Later on this strategy was further extended to prepare highly porous $\mathrm{Cr}$ MOFs through an easy solvothermal post-synthetic treatment starting from pre-formed Fe-MOFs. ${ }^{19}$ However, the synthesis of bi-metallic kinetic phases, such as MIL-101, remains challenging as it requires a careful tuning of the kinetic reactivity of the cations.

Preparation of heterometallic MOFs is a well-established strategy to optimize the catalytic activity of these materials. ${ }^{20-}$

${ }^{23}$ For instance, doping MIL-100(Fe) with Ni species was found a convenient way to both increase the activity of the MOF catalyst, while preserving the good chemical stability of the bare Fe-MOF.

Herein, the preparation of a robust and stable mixed-metal MIL-101(Cr/Fe) structure in various $\mathrm{Fe}^{3+}$ proportions up to 21 wt\% is achieved through a direct hydrothermal synthesis avoiding the use of toxic HF. ${ }^{57} \mathrm{Fe}$ Mössbauer spectrometry supports the successful incorporation of $\mathrm{Fe}^{3+}$ cations within the crystal structure of the mixed-metal MIL-101(Cr/Fe) solids. Catalytic data for the Prins reaction indicate that the mixedmetal MIL-101(Cr/Fe) materials exhibit both an increased activity in comparison with the pure MIL-101(Cr) material, as well as a strongly enhanced chemical stability compared with the single-metal MIL-101(Fe) solid. The mesoporosity of the mixed-metal MIL-101(Cr/Fe) was found to make this material more adequate as catalyst to promote the Prins addition of bulky substrates compared to MIL-100(Fe), most likely due to a favored substrate diffusion. In addition, a good relationship between the $\mathrm{Fe}^{3+}$ proportion in the $\mathrm{MIL}-101(\mathrm{Cr} / \mathrm{Fe})$ catalysts and the observed catalytic activity has been found. Stability data indicate that $\mathrm{MIL}-101(\mathrm{Cr} / \mathrm{Fe})$ solid acts as a true heterogeneous catalyst that can be reused maintaining its initial crystallinity without undergoing metal leaching. This work illustrates the successful design of heterometallic MOFs exhibiting a superior catalytic activity by having one metal with a predominant role in maintaining the crystal structure $\left(\mathrm{Cr}^{3+}\right.$ in the present case) and a second one enhancing the catalytic activity (Fe ${ }^{3+}$ in MIL-101).

\section{Results and discussion}

\section{Catalyst preparation}

The synthesis of MIL-101(Cr/Fe) by direct hydrothermal synthesis has been already reported. ${ }^{24}$ However, the previously reported synthetic procedure used hydrofluoric acid (HF) as acidic modulator/mineralizing agent. HF is a highly hazardous liquid (highly toxic and corrosive, as well as contact poison) and, therefore, not suitable for green and sustainable syntheses that are targeted nowadays, particularly for large scale preparation. A hydrothermal synthesis without HF was recently reported, but pure MIL-101(Cr/Fe) phase was only obtained for low Fe content $(10 \mathrm{wt} \%) .^{25}$ In the present case, the target was to introduce much larger $\mathrm{Fe}$ proportions reaching about $20 \mathrm{wt} \%$ of the total $\mathrm{Cr}\left(\mathrm{NO}_{3}\right)_{3} \cdot 9 \mathrm{H}_{2} \mathrm{O}$ replaced by $\mathrm{Fe}\left(\mathrm{NO}_{3}\right)_{3} \cdot 9 \mathrm{H}_{2} \mathrm{O}$. Consequently, the reported synthesis was optimized to avoid the use of HF, while achieving higher Fe content.

For the synthesis of pure and well crystallized MIL$101(\mathrm{Cr} / \mathrm{Fe})$ solids, one of the most difficult challenge to overcome is the competition between the crystallization of two other polymorphs (i.e. same chemical composition, but different structure) typically obtained when dealing with $\mathrm{M}^{3+}$ cations and terephthalic acid: namely MIL-101, ${ }^{9}$ MIL- $88^{26}$ and the thermodynamically preferred phase MIL-53. ${ }^{27,28}$ The use of mixed-metals with different reactivity is also known to modify the crystallization process and influence polymorph formation, not mentioning the risk to form metal oxides. ${ }^{29}$ Therefore, attempts to obtain mixed-metal MIL-101(Cr/Fe) using iron nitrate as $\mathrm{Fe}^{3+}$ source and similar synthetic conditions $\left(220{ }^{\circ} \mathrm{C}, 8 \mathrm{~h}\right)$ as those used for the pure MIL$101(\mathrm{Cr}){ }^{30}$ resulted only in mixtures of MIL-101/MIL-88B (Figure SI-1), possibly due to the higher reactivity of iron cations that drives the phase formation towards MIL-88B. The addition of non-toxic acidic modulators, such as acetic acid (HOAC) was also explored, but it resulted as well in MIL101/MIL-88B mixtures (Figure SI-1). A possible way to address this difference in reactivity between $\mathrm{Fe}^{3+}$ and $\mathrm{Cr}^{3+}$ is the use of a less reactive iron source such as metal iron. $\mathrm{Fe}^{0}$ has already successfully been used for the preparation of the mixed metal MIL-53(Cr/Fe). ${ }^{23}$ As seen in Figure $\mathrm{SI}-2$, the use of $\mathrm{Fe}^{0}$ drastically limited the formation of MIL-88B phase, compared to the use of iron nitrate, but did not fully prevented its formation. The use of HOAc did not improve the phase purity and resulted in mixture of MIL-101/MIL-88B phases (Figure SI2). It was, thus, concluded that this acid modulator was not adequate for the formation of a pure $\mathrm{MIL}-101(\mathrm{Cr} / \mathrm{Fe})$ phase.

Basic additives, such as $\mathrm{NaOH}, \mathrm{KOH}$ and tetramethylammonium hydroxide (TMAOH), have also been studied for the synthesis of MIL-101 materials. Their use has been reported to enhance the solubility of the terephthalic acid and to favor the nucleation process, as the $\mathrm{pH}$ conditions are shifted around $\mathrm{pH} 6$, thus promoting the synthesis of MIL101. MIL-101(Cr) synthesized in the presence of low concentrations of TMAOH showed a good crystallinity, high specific surface area and the formation of pure phases. ${ }^{31,32}$ It was hence of interest to investigate the use of this basic additive for the formation of the mixed metal MIL-101(Cr/Fe). To minimize the formation of the thermodynamic phase MIL$53(\mathrm{Cr})$, the reaction temperature was decreased, while the reaction time increased and various $\mathrm{TMAOH}$ concentrations were tested $(0.0125-0.09 \mathrm{M})$. It was found that the purity of 
MIL-101 ( $\mathrm{Cr} / \mathrm{Fe})$ varied linearly with TMAOH concentrations (Figure SI-3). Concentrations above $0.06 \mathrm{M}$ promoted mostly the synthesis of MIL-101 phase, whereas lower concentrations resulted in traces of the MIL-53 phase. When TMAOH concentration was increased above $0.07 \mathrm{M}$, the crystallinity of the product significantly decreased until an amorphous solid was obtained at $0.09 \mathrm{M}$ of $\mathrm{TMAOH}$. These results are in agreement with previous studies that showed the effect of the TMAOH concentration on the crystallinity of MIL-101. ${ }^{32}$

Further optimization was achieved by further decrease of the reaction temperature minimizing oxide formation. Two

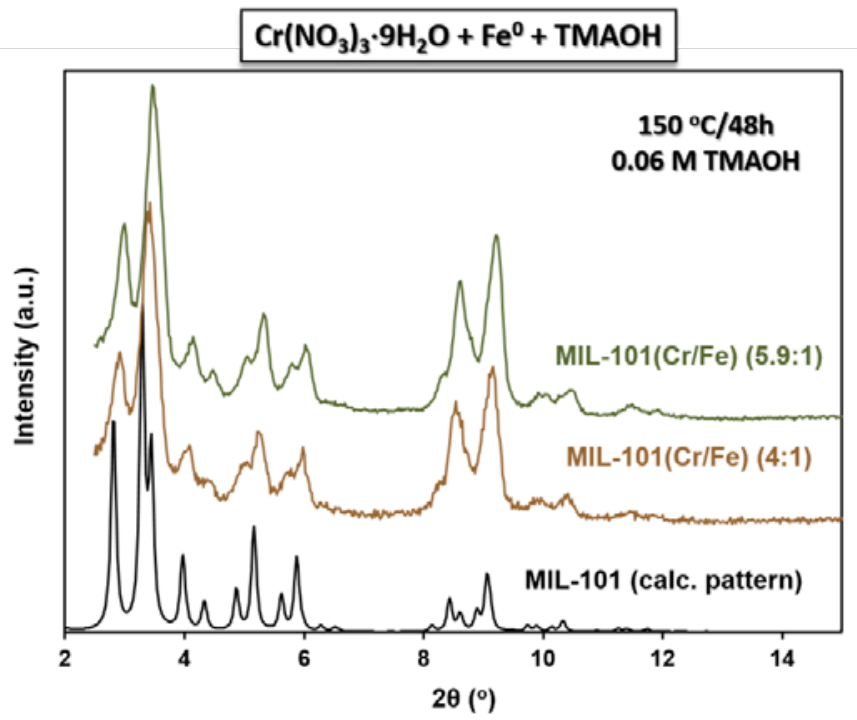

pure MIL-101(Cr/Fe) materials with 4:1 and 5.9:1 Cr:Fe ratios were finally successfully obtained by using $\mathrm{TMAOH}$ as basic additive at $0.06 \mathrm{M}$ at $150{ }^{\circ} \mathrm{C}$. Both MIL-101(Cr/Fe) materials

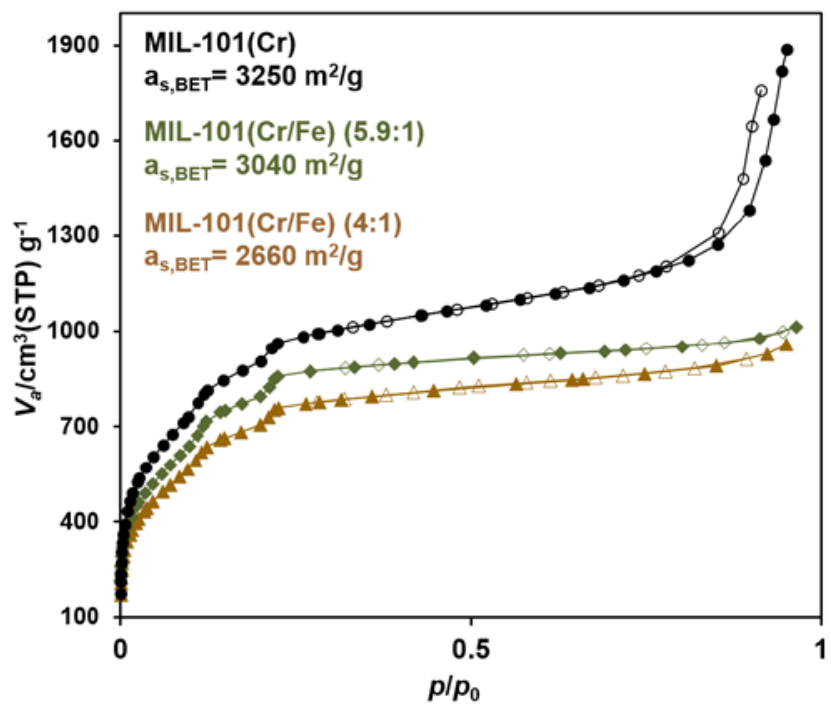

showed characteristic Bragg peaks of MIL-101, without any additional peaks, which confirmed the formation of a pure phase (Figure 1).

Figure 1: Normalized PXRD patterns $(\lambda=1.54 \AA)$ of MIL$101(\mathrm{Cr} / \mathrm{Fe})(4: 1)$ and MIL-101(Cr/Fe) (5.9:1), compared with the calculated pattern of MIL-101(Cr).
Figure 2: $\mathrm{N}_{2}$ sorption isotherms of MIL-101 (Cr) (black cycles), MIL-101(Cr/Fe) (4:1) (brown triangles) and MIL-101(Cr/Fe) (5.9:1) (green diamonds) at $77 \mathrm{~K}\left(\mathrm{P}_{0}=1 \mathrm{~atm}\right)$.

The $\mathrm{Cr}$ and Fe atomic content was analyzed by EDX (average of 12 random points) and confirmed by ICP-OES. The composition was found to be $81 \pm 2 \% \mathrm{Cr}$ and $19 \pm 2 \%$ Fe for MIL$101(\mathrm{Cr} / \mathrm{Fe})(4: 1,21 \mathrm{wt} \%)$ and $85 \pm 1 \% \mathrm{Cr}$ and $15 \pm 1 \%$ Fe for MIL-101(Cr/Fe) (5.9:1, 14 wt\%). The low standard deviation as well as the identical values obtained by EDX and ICP-OES, suggest a homogeneous dispersion of iron in the sample. The chemical formulae of the MOFs deduced from the EDX are $\mathrm{Cr}_{2.4} \mathrm{Fe}_{0.6} \mathrm{OH}\left(\mathrm{H}_{2} \mathrm{O}\right)_{2} \mathrm{O}\left[\left(\mathrm{O}_{2} \mathrm{C}\right)-\mathrm{C}_{6} \mathrm{H}_{4}-\left(\mathrm{CO}_{2}\right)\right]_{3}$,

$\mathrm{Cr}_{2.57} \mathrm{Fe}_{0.43} \mathrm{OH}\left(\mathrm{H}_{2} \mathrm{O}\right)_{2} \mathrm{O}\left[\left(\mathrm{O}_{2} \mathrm{C}\right)-\mathrm{C}_{6} \mathrm{H}_{4}-\left(\mathrm{CO}_{2}\right)\right]_{3}$ for $\mathrm{MIL}-101(\mathrm{Cr} / \mathrm{Fe})$ (4:1) and MIL-101(Cr/Fe) (5.9:1), respectively.

SEM analysis on the two mixed-metal MIL-101(Cr/Fe) solids revealed the formation of particles, without a well-defined morphology. Nonetheless, both MOFs showed uniform particles of around $100 \mathrm{~nm}$ (Figure SI-4). The TGA curves of the two mixed metal MOFs were compared with that of MIL101(Cr) (Figure SI-5). The thermal degradation of the structures was observed around $300{ }^{\circ} \mathrm{C}$ under oxygen, which is similar to the pure $\mathrm{MIL}-101(\mathrm{Cr}),{ }^{9}$ indicating that the incorporation of $\mathrm{Fe}^{3+}$ cations, does not affect the thermal stability of the framework. The percentage of $\mathrm{Cr}_{2} \mathrm{O}_{3}$ residue obtained in the case of MIL-101(Cr) (31\%) was found to be slightly lower than the global percentage of the oxide residues $\left(\mathrm{Cr}_{2} \mathrm{O}_{3}+\mathrm{Fe}_{2} \mathrm{O}_{3}\right)$ formed in the case of the mixed-metal MOFs: $35 \%$ for MIL-101(Cr/Fe) $(4: 1)$ and $32 \%$ for MIL-101(Cr/Fe) (5.9:1). This may indicate that a small part of the metal precursors used for the synthesis of the MOFs could have formed oxides that could not be removed during the activation of the samples. $\mathrm{N}_{2}$ sorption measurements of the mixed-metal MOFs exhibit type I isotherms, with secondary uptakes at $\mathrm{p} / \mathrm{p}_{0}$ $\sim 0.1$ and $\mathrm{p} / \mathrm{p}_{0} \sim 0.2$, which are characteristic of the two microporous windows (pentagonal and hexagonal) of the two mesoporous cages (Figure 2). The apparent BET surface areas were calculated to be $2700 \pm 100$ and $3040 \pm 60 \mathrm{~m}_{2} / \mathrm{g}$ for MIL$101(\mathrm{Cr} / \mathrm{Fe})(4: 1)$ and MIL-101(Cr/Fe) (5.9:1), respectively. The pore size distributions of the pure MIL-101(Cr) and the mixedmetal MIL-101(Cr/Fe) are very close to each other (Figure SI-6), suggesting identical pores structure and that both metals are incorporated in the framework. The obtained mixed-metal MOFs exhibited slightly lower surface area than that for the pure MIL-101(Cr) $\left(3250 \mathrm{~m}^{2} / \mathrm{g}\right)$, which could be related to the presence of small percentages of metal oxides, in agreement with the TGA measurements.

${ }^{57}$ Fe Mössbauer spectrometry was used to gain information about the oxidation and the spin state of the Fe atoms, along with its electronic environment, in order to confirm that the Fe of the mixed MOFs was indeed incorporated in the lattice and to exclude the possibility of Fe being mainly under the form of Fe oxides or hydroxides. The transmission Mössbauer spectra of MIL-101(Cr/Fe) (4:1) recorded at $300 \mathrm{~K}$ and $77 \mathrm{~K}$, consist of quadrupolar doublets with broadened and overlapped lines, indicative of different environments of Fe atoms (Figure 3, SI-7 and $\mathrm{SI}-8$ ). They were first recorded at $4 \mathrm{~mm} / \mathrm{s}$ to check that the 
samples did not contain any High Spin (HS) Fe(II) species and then at $2 \mathrm{~mm} / \mathrm{s}$. Figure 3 illustrates only the spectra recorded at $2 \mathrm{~mm} / \mathrm{s}$. Different fitting models could be applied with two components or three components, resulting in the same mean values of isomer shift $(0.33$ and $0.48 \mathrm{~mm} / \mathrm{s}$ at $300 \mathrm{~K}$ and $77 \mathrm{~K}$, respectively) and quadrupolar splitting $(0.68$ and $0.74 \mathrm{~mm} / \mathrm{s}$ at $300 \mathrm{~K}$ and $77 \mathrm{~K}$, respectively). These values are consistent with the presence of $\mathrm{HS} \mathrm{Fe}^{3+}$ in an octahedral environmental, suggesting that they may be located in the octahedral units of the inorganic building blocks. ${ }^{33-35}$ This is further supported by the similarity between the Mössbauer spectra of the mixed MIL-101(Cr/Fe) (4:1) and the reported spectrum of MIL100(Fe) (Figure 3 and Figure SI-8). ${ }^{35}$ The isomer shift values of MIL-100(Fe) are significantly higher $(0.42$ and $0.54 \mathrm{~mm} / \mathrm{s}$ at $300 \mathrm{~K}$ and $77 \mathrm{~K}$, respectively). This difference could result from the amount of fluorine ions contained in the structure, as the presence of $\mathrm{F}$ ions in the $\mathrm{Fe}$ environment results in higher isomer shifts than Fe surrounded by $0 .^{23}$ It should be noted that in the reported Mössbauer spectrum of MIL-100(Fe), the synthesis was performed in presence of KF and it has been previously demonstrated that the resulting structure has one fluorine atom per Fe trimer. ${ }^{35}$ However, in the case of MIL$101(\mathrm{Cr} / \mathrm{Fe})$, the synthesis was performed without fluorine, and the corresponding coordination position in the structure is occupied by hydroxyl ions. ${ }^{18}$ In the present mixed-metal MIL$101(\mathrm{Cr} / \mathrm{Fe})$, the mean values of isomer shift are rather typical of $\mathrm{Fe}^{3+}$ surrounded by oxygen or hydroxyl groups, in fair agreement with the absence of KF during the synthesis of MIL$101(\mathrm{Cr} / \mathrm{Fe})$. When the content of $\mathrm{Fe}$ incorporated in the synthesis was decreased (ratio $\mathrm{Cr} / \mathrm{Fe} 5.9: 1$ ), no significant differences were observed in the Mössbauer spectrum (Figure 3), except for a slight increase of the quadrupolar doublet asymmetry. The presence of water molecules in the

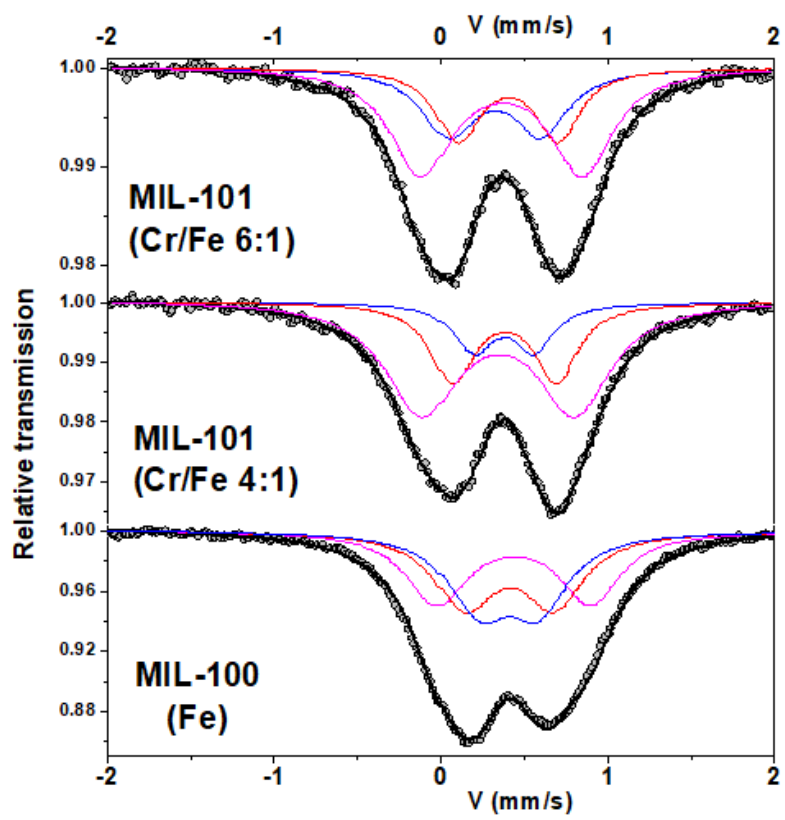

framework actually influences the Mössbauer spectra and may be responsible for this difference. It is important to emphasize that the lack of resolution of the hyperfine structure does not allow excluding the presence of traces of iron $^{3+}$ oxides in MIL$101(\mathrm{Ce} / \mathrm{Fe})$ samples, similarly to the case of MIL-100(Fe).

Our strategy therefore allows the preparation of MIL$101(\mathrm{Cr} / \mathrm{Fe})$ solid with a $\mathrm{Fe}^{3+}$ loading up to $21 \mathrm{wt} \%$ using a HF-

Figure 3: Mössbauer transmission spectra of $\mathrm{MIL}-101(\mathrm{Cr} / \mathrm{Fe})$ (5.9:1), MIL-101(Cr/Fe) (4:1) and MIL-100(Fe), recorded at 77 $\mathrm{K}$.

free route. It should be commented that the mesoporous rigid MIL-101 phase exhibits higher BET surface areas and porosity (3250 $\mathrm{m}^{2} \mathrm{~g}^{-1}$ and $1.2 \mathrm{~cm}^{3} \mathrm{~g}^{-1}$ ) compared to that of the flexible microporous MIL-88B ( $\left.<500 \mathrm{mg}^{2} \mathrm{~g}^{-1} ; 0.6 \mathrm{~cm}^{3} \mathrm{~g}^{-1}\right)$, whose pores undergo a strong contraction upon drying. Therefore, MIL-101 is better suited as heterogeneous catalyst in comparison to MIL-88B, which shows important diffusion limitations.

\section{Catalytic activity}

The main purpose of this study was to show that it is possible to overcome the intrinsic structural instability of the single metal MIL-101(Fe) solid by exploiting the structural stability of MIL-101(Cr), while introducing in nodal positions some $\mathrm{Fe}^{3+}$ sites in adequate proportion to preserve structural stability due to the prevalence of $\mathrm{Cr}^{3+}$, but still sufficiently high to achieve optimal catalytic activity.

To prove the concept of one metal maintaining the MOF structure and other acting as catalytic center, the MIL$101(\mathrm{Cr} / \mathrm{Fe})(4: 1)$ sample having about $21 \mathrm{wt} \% \mathrm{Fe}^{3+}$ was initially selected and its catalytic activity studied for the benchmark Lewis acid catalyzed addition of $\beta$-pinene to formaldehyde to afford [2-(7,7-dimethyl-4-bicyclo[3.1.1]hept-3-enyl)-ethanol], commonly known as Nopol (Scheme 1). Nopol is an important commodity with woody camphoraceous scent used in perfumery for the large scale production of fragrances. ${ }^{8,36}$ It is also used in the preparation of pesticides in the agrochemical industry. ${ }^{8,36}$ This Prins reaction has been widely studied in the presence of a large range of homogenous (i.e. $\mathrm{HCl}, \mathrm{SnCl}_{2}, \mathrm{ZnCl}_{2}$ etc.) and heterogeneous catalysts including MOFs, observing that Nopol formation is accompanied by the presence of some byproducts, 10-pinen-3-ol being the most common one. ${ }^{7}$

Particularly, formation of Nopol has been reported already using MIL-100(Fe) or MIL-100(Cr) as heterogeneous catalysts, observing that these materials efficiently promote the addition reaction, without undergoing metal leaching and exhibiting reusability in consecutive batch reactions. ${ }^{8}$

In the present study a preliminary control experiment in

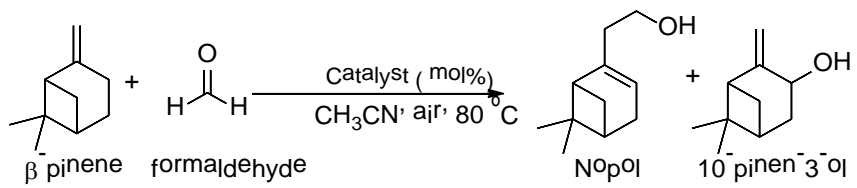

the absence of catalyst shows that $\beta$-pinene conversion does not take place under the present reaction conditions. In contrast, when MIL-101(Cr) was present in the reaction, the addition reaction occurs resulting in the formation of Nopol as 
main product together with 10-pinen-3-ol (Table S1), reaching a conversion of $26 \%$ at $30 \mathrm{~h}$ (Figure 4). The use of MIL-101(Fe) or MIL-88B(Fe) as iron-based catalysts resulted in a slight increase of the catalytic activity ( $36 \% \beta$-pinene conversion at $30 \mathrm{~h}$ ) and formation of 10-pinen-3-ol (Table S1) respect to the use of MIL-101(Cr).

Scheme 1. Prins reaction of $\beta$-pinene with formaldehyde and the chemical structure of the two products observed in the present reaction.

PXRD patterns of the used MOFs revealed that MIL-101(Fe) is, however, unstable under the present reaction conditions and is largely transformed into the $\mathrm{MIL}-88 \mathrm{~B}(\mathrm{Fe})$ structure (Figure $\mathrm{SI}-9)$. Importantly, the use of the novel MIL-101(Cr/Fe) (4:1) solid resulted in a much more robust material, exhibiting a significantly higher catalytic activity ( $85 \%$ at $30 \mathrm{~h})$ than MIL101(Cr), MIL-101(Fe) or MIL-88B(Fe) and even higher than the homogeneous $\mathrm{Fe}^{3+}$ acetate catalyst (Figure 4). It should be noted that the higher catalytic activity of these Fe-based MOFs results, however, in the formation of higher amounts of 10pinen-3-ol respect to the less active but more selective MIL$101(\mathrm{Cr})$ catalyst (Table S1).

To put the catalytic activity of MIL-101(Cr/Fe) (4:1) into context, MIL-100(Fe) with all the metal nodes constituted by iron was used as reference. MIL-100(Fe) exhibited only slightly lower activity than MIL-101(Cr/Fe) (4:1) (Figure 4 and Table $\mathrm{S} 1)$, whose $\mathrm{Fe}^{3+}$ content is about 5 times lower. Thus, it seems that the $\mathrm{Fe}^{3+}$ sites of MIL-101(Cr/Fe) (4:1) are intrinsically more active than the ones of MIL-100(Fe). The lower intrinsic activity of $\mathrm{Fe}^{3+}$ in $\mathrm{MIL}-100(\mathrm{Fe})$ can be understood considering the smaller dimensions of windows (0.55 and $0.86 \mathrm{~nm})$ and cavities (2.4 and $2.9 \mathrm{~nm}$ ) in MIL-100 respect to the MIL-101 structure, imposing diffusion limitations to the reaction. The higher activity of MIL-101(Cr/Fe) (4:1) respect to MIL-101(Cr) can also be understood considering the benefits of combining the highly porous and stable MIL-101(Cr) structure, with a large percentage of $\mathrm{Fe}^{3+}$ ions with higher intrinsic catalytic activity than $\mathrm{Cr}^{3+}$. In this way, even though the amount of $\mathrm{Fe}^{3+}$ in the catalyst is only $21 \mathrm{wt} \%$, the activity of $\mathrm{Fe}^{3+}$ ions in this MIL-101 structure is similar or higher than when homometallic MIL-100(Fe) or MIL88-(Fe) are used as catalyst, due to a more impeded accessibility to the $\mathrm{Fe}^{3+}$ sites.

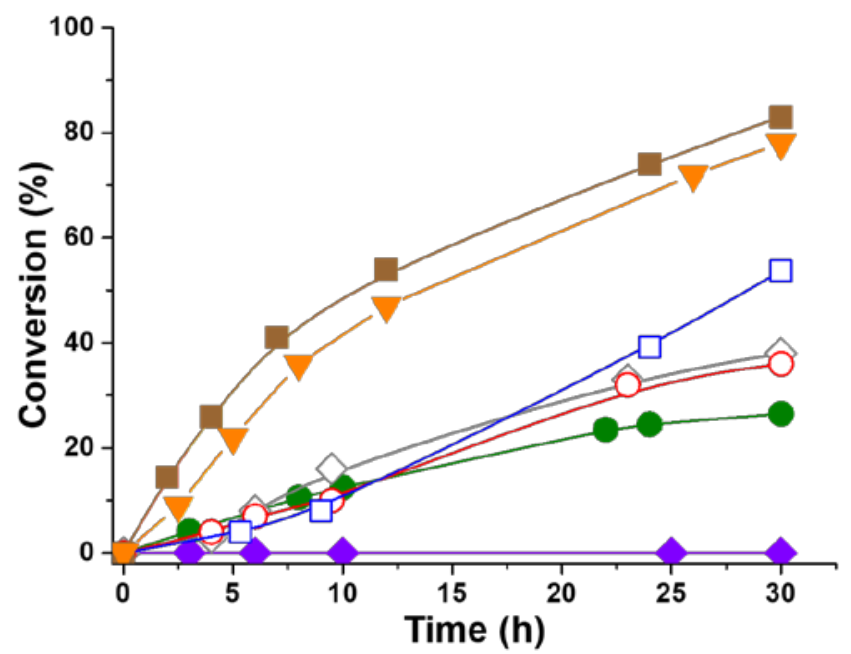

Figure 4. Catalytic activity for $\beta$-pinene using MIL-101(Cr/Fe)

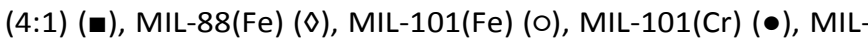
$100(\mathrm{Fe})(\boldsymbol{\nabla}), \mathrm{Fe}^{3+}$ acetate $(\square)$ and in the absence of catalyst $(\diamond)$. Reaction conditions: Catalyst $(0.02 \mathrm{mmol}$ of metal), $\beta$ pinene $(800 \mu \mathrm{L}, 5 \mathrm{mmol})$, formaldehyde $(750 \mu \mathrm{L}, 5 \mathrm{mmol})$, acetonitrile $(1.26 \mathrm{~mL}), 80^{\circ} \mathrm{C}$.

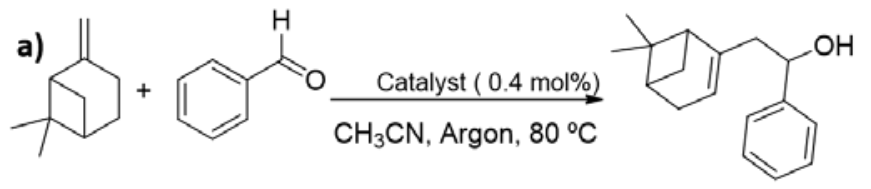

b)

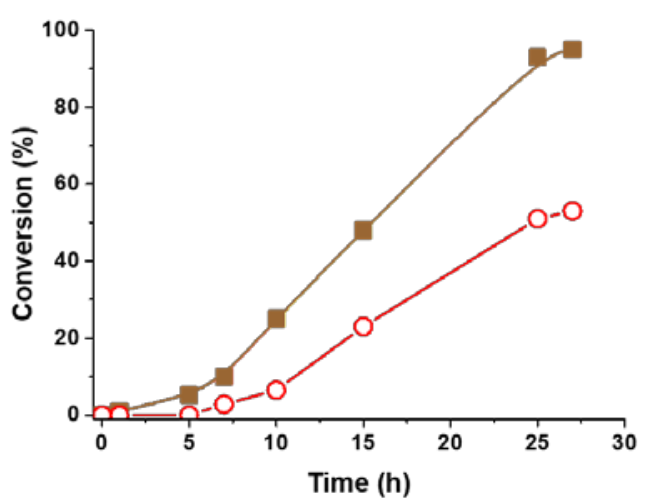

Figure 5. a) Prins addition of $\beta$-pinene and benzaldehyde. b) Temporal conversion plot of $\beta$-pinene using MIL-101(Cr/Fe) $(4: 1)(\square)$ or MIL-100(Fe) (O) as catalyst. Reaction conditions: Catalyst $(0.02 \mathrm{mmol}$ of $\mathrm{Cr}+\mathrm{Fe}), \beta$-pinene $(800 \mu \mathrm{L}, 5 \mathrm{mmol})$, benzaldehyde ( $x x x \mu \mathrm{L}, 5 \mathrm{mmol}$ ), acetonitrile $(1.26 \mathrm{~mL}), 80^{\circ} \mathrm{C}$.

In agreement with the above proposal to rationalize the activity of mixed-metal $\mathrm{Cr} / \mathrm{Fe} \mathrm{MOF}$, the benefits of MIL$101(\mathrm{Cr} / \mathrm{Fe})(4: 1)$ respect to the MIL-100(Fe) as solid catalyst to promote the Prins reaction of $\beta$-pinene are even more clearly evidenced when a bulkier aldehyde such as benzaldehyde is used as substrate. In this case, the use of argon atmosphere during the reaction allowed to achieve a selective addition of $\beta$-pinene and benzaldehyde without formation of oxidized reaction products. Figure 5 shows a comparison of the timeconversion plot under the same conditions for the Prins reaction with benzaldehyde as reagent using MIL-101(Cr/Fe) (4:1) or MIL-100(Fe) as catalyst. As it can be seen the activity of MIL-101(Cr/Fe) (4:1) is higher than that of MIL-100(Fe) in spite of the 5 -fold higher $\mathrm{Fe}^{3+}$ content of the latter.

To determine the influence of the $\mathrm{Fe}^{3+}$ content present in the mixed-metal MIL-101( $\mathrm{Cr} / \mathrm{Fe})$ solid on the catalytic activity for the Prins reaction, three MIL-101(Cr/Fe) containing different $\mathrm{Fe}^{3+}$ contents with values 2.5, 14 and 21 wt\% (ratio $\mathrm{Cr} / \mathrm{Fe}$ 36:1, 5.9:1, 4:1, respectively) were tested. Figure 6 presents the time-conversion plots for the Prins reaction promoted by these three mixed-metals MIL-101(Cr/Fe) solids. By plotting the initial reaction rate vs. the Fe content it was observed that, although $\mathrm{Cr}^{3+}$ also catalyses the reaction as it can be deduced from the initial reaction rate value at $0 \mathrm{Fe}^{3+}$ 
content, the initial reaction rate increases with the $\mathrm{Fe}^{3+}$ content. This increase in the initial reaction rate means that $\mathrm{Fe}^{3+}$ is more active than $\mathrm{Cr}^{3+}$ to promote the reaction. Furthermore, an increase of TOF value at higher $\mathrm{Fe}^{3+}$ loadings was observed. In principle, the TOF value should be constant if all the $\mathrm{Fe}^{3+}$ sites were equally active. Therefore, the TOF increase along the $\mathrm{Fe}^{3+}$ percentage suggests some degree of

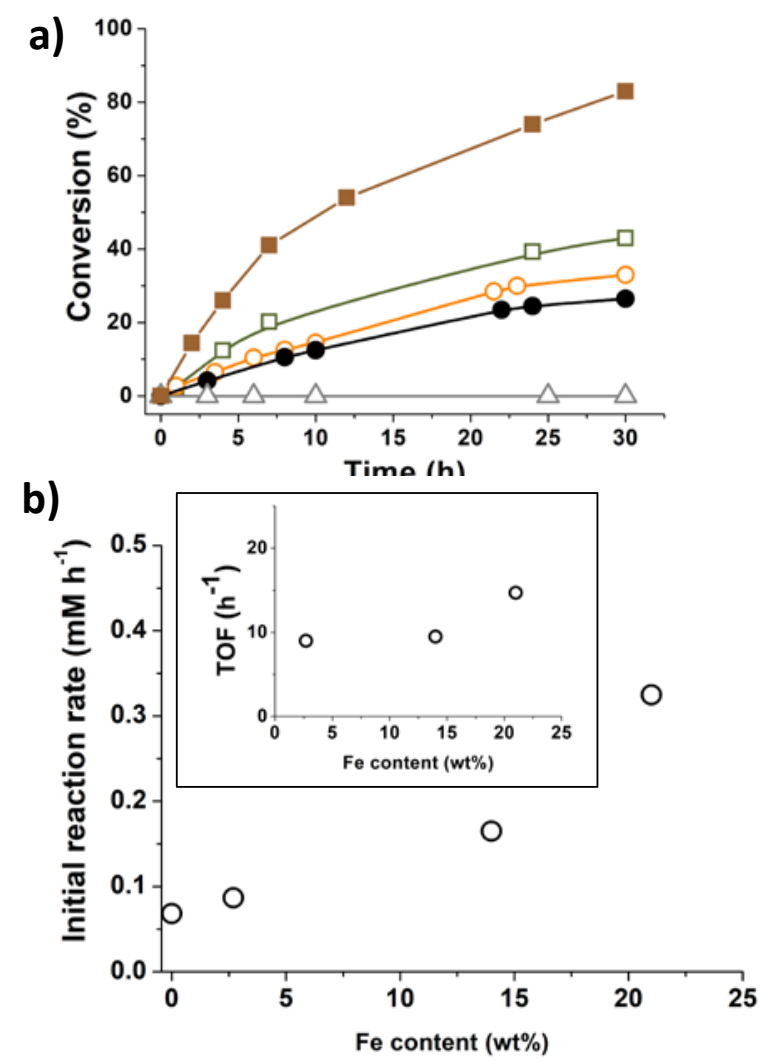

cooperation among the $\mathrm{Fe}^{3+}$ sites. Furthermore, the higher the iron content on the mixed-metal MIL-101(Cr/Fe) solid the higher the activity accompanied, however, by increased formation of the by-product 10-pinen-3-ol (Figure 6 and Table S1).

Figure 6. (a) Time-conversion plot for the Prins reaction between $\beta$-pinene and formaldehyde in the presence of MIL101(Cr/Fe) (4:1) (匹), MIL-101(Cr/Fe) (5.9:1) (口), MIL-101(Cr/Fe) $(36: 1)(0), \mathrm{MIL}-101(\mathrm{Cr})(\bullet)$ and in the absence of catalyst $(\Delta)$. (b) Influence of the iron MIL-101 iron content on the initial reaction. The inset shows the influence of the iron content on the TOF; note that the activity of the MIL-101(Cr) has been subtracted to calculate the TON of mixed-metal MIL$101(\mathrm{Cr} / \mathrm{Fe})$ solids. Reaction conditions: Catalyst $(0.02 \mathrm{mmol}$ of $\mathrm{Fe}+\mathrm{Cr}), \beta$-pinene $(800 \mu \mathrm{L}, 5 \mathrm{mmol})$, formaldehyde $(750 \mu \mathrm{L}, 5$ $\mathrm{mmol})$, acetonitrile $(1.26 \mathrm{~mL}), 80^{\circ} \mathrm{C}$.

The catalytic activity of mixed-metal MIL-101(Cr/Fe) (4:1) was finally compared with that of homogeneous $\mathrm{Cr}^{3+}$ acetate and heterogeneous $\mathrm{Cr}_{2} \mathrm{O}_{3}$ or $\mathrm{Fe}_{2} \mathrm{O}_{3}$ solids (Figure 7). MIL$101(\mathrm{Cr} / \mathrm{Fe})(4: 1)$ exhibits the highest initial reaction rate in the series followed by the soluble $\mathrm{Cr}^{3+}$ salt. This observation is in agreement with previous results showing the benefits of metal ion isolation by immobilization in highly accessible metal clusters of porous MOFs acting as single-site catalysts. ${ }^{37}$ On one hand, they exhibit similar or higher intrinsic activity to that of the homogeneous sites catalysts, and on the other, they undergo much slower deactivation by aggregation due to site immobilization.

As mentioned above and shown in Scheme 1, besides Nopol the formation of 10-pinen-3-ol was also observed in the presence of MIL-101. Selectivity values are presented in Figure 7b. As described in previous reports, 10-pinen-3-ol arises from the allylic oxidation of $\beta$-pinene by molecular oxygen. ${ }^{38,39}$ There are in the literature several studies showing that, besides as solid Lewis acid, MIL-101 can act also as oxidation catalyst. ${ }^{14,} 40$ Under the present reaction conditions, the highest conversion and highest Nopol selectivity at final reaction time ( $30 \mathrm{~h}$ ) was achieved using the homogeneous $\mathrm{Cr}^{3+}$ salt. Importantly, the use of the heterogeneous MIL-101( $\mathrm{Cr} / \mathrm{Fe})$ $(4: 1)$ catalyst results in a higher catalytic activity and higher Nopol selectivity respect to the metal oxides $\gamma-\mathrm{Fe}_{2} \mathrm{O}_{3}$ or $\alpha$ $\mathrm{Cr}_{2} \mathrm{O}_{3}$ (Figure 6 and Table S1).

In the case of the mixed-metal MIL101(Cr/Fe) (4:1), the heterogeneity of the reaction was supported by performing a hot filtration test, observing that the reaction almost completely stopped after filtration of the solid (Figure 7). The minor conversion from 26 to $30 \%$ from 4 to $30 \mathrm{~h}$ in the absence of solid after filtration of the catalyst was due to the occurrence of $\beta$-pinene oxidation to 10-pinen-3-ol, but not to the $\beta$-pinene addition to formaldehyde.
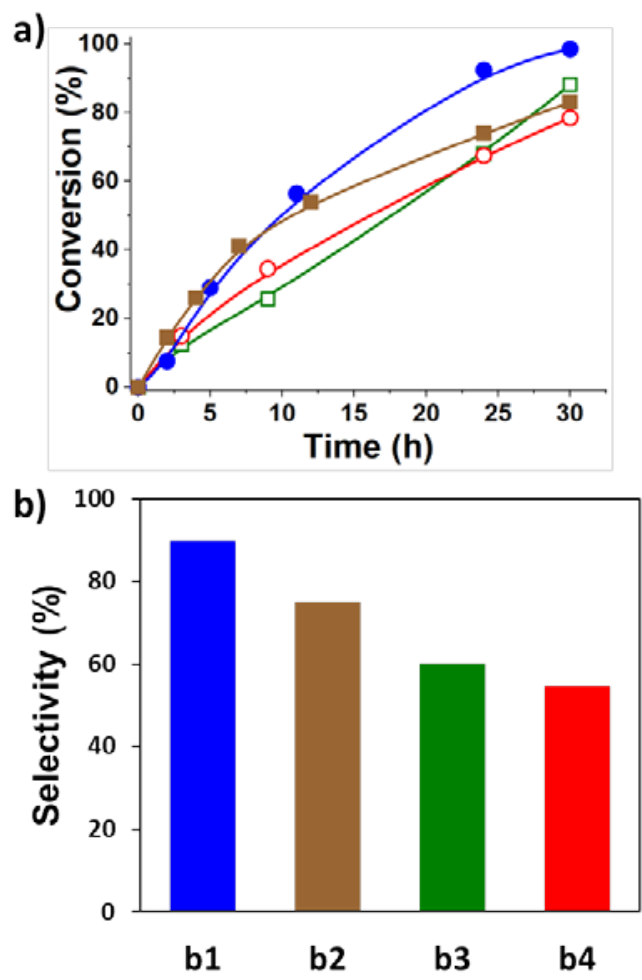


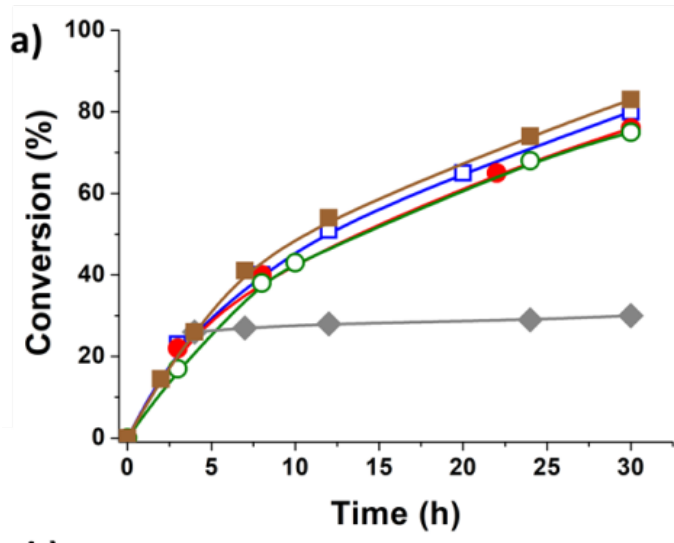

b)

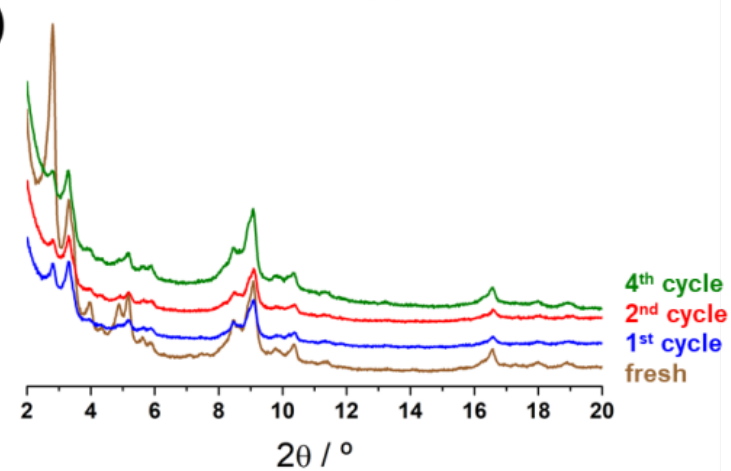

Figure 7. (a): Time-conversion plots of $\beta$-pinene using MIL$101(\mathrm{Fe} / \mathrm{Cr}$ ) (4:1) ( $\square), \mathrm{Cr}^{3+}$ acetate hydroxyde $(\bullet), \mathrm{Fe}_{2} \mathrm{O}_{3}(\square)$ or $\mathrm{Cr}_{2} \mathrm{O}_{3}(\mathrm{O})$ as catalysts and (b): Nopol selectivity for $\mathrm{Cr}^{3+}$ acetate hydroxide (b1), MIL-101(Fe/Cr) (4:1) (b2), $\mathrm{Fe}_{2} \mathrm{O}_{3}$ (b3) or $\mathrm{Cr}_{2} \mathrm{O}_{3}$ (b4) as catalysts. Reaction conditions: Catalyst $(0.02 \mathrm{mmol}$ metal), $\beta$-pinene $(800 \mu \mathrm{L}, 5 \mathrm{mmol})$, formaldehyde $(750 \mu \mathrm{L}, 5$ $\mathrm{mmol}), \mathrm{CH}_{3} \mathrm{CN}(1.15 \mathrm{~mL}), 80^{\circ} \mathrm{C}$.

Figure 8. (a) Hot filtration and reusability tests $1^{\text {st }}$ use $(\boldsymbol{\square}), 2^{\text {nd }}$ use $(\square), 3^{\text {th }}$ use $(\bullet), 4^{\text {th }}$ use $(0)$ and without catalyst $(\bullet)$. (b) PXRD patterns for the fresh and used MIL-101(Cr/Fe) (4:1). Reaction conditions: Catalyst $(0.02 \mathrm{mmol}$ metal), $\beta$-pinene (800 $\mu \mathrm{L}, 5 \mathrm{mmol})$, formaldehyde $(750 \mu \mathrm{L}, 5 \mathrm{mmol}), \mathrm{CH}_{3} \mathrm{CN}(1.15 \mathrm{~mL})$, 80 ㅇ.

Catalyst stability was finally studied by performing four consecutive runs using the same MIL-101(Cr/Fe) (4:1) sample. Comparison of the temporal profiles of first and consecutive reactions showed only a slight decrease of the catalytic activity, while maintaining the same product selectivity of about $75 \%$ (Figure 8a). This partial deactivation is not due to degradation of the MIL-101(Cr/Fe) (4:1) catalyst, since all PXRD patterns recorded after each run are comparable to the fresh material (Figure $8(\mathrm{~b})$ ). A loss of intensity of the first Bragg reflexions was observed, likely due to remaining reactants in the pores. Analysis by ICP-OES of the chromium and iron content in the liquid reaction phase after filtration of the solid catalyst showed that the concentration of these metals in the liquid phase corresponds to about 0.002 and $0.02 \mathrm{wt} \%$ of the initial chromium and iron content of the fresh catalyst, respectively, in agreement with the absence of degradation of the MIL-101 $(\mathrm{Cr} / \mathrm{Fe})$. A minor catalyst deactivation was observed upon cycles which might be attributed to adsorption of reaction products or by-products. It is important to note that all molecules involved in the catalytic process have molecular dimensions $<1 \mathrm{~nm}$ and are suitable for entering the pores of the catalyst through the windows (Figure SI-10). However, despite the favored molecule diffusion, a partial blocking of the pores and/or active sites may not be excluded, which may cause an apparent decrease on the performance of the material. To corroborate the possibility of products or byproducts adsorption in consecutive cycles, $\mathrm{N}_{2}$ physisorption were conducted for the used and washed MIL-101(Cr/Fe) material, showing a slightly lower surface area as compared to the fresh catalyst, whereas a drastic loss of sorption capacity was observed when the catalyst was not washed, pointing to the presence of physisorbed molecules filling the pores (Figure $\mathrm{SI}-11$ in supporting information).

\section{Characterization of the acid sites}

In order to get some insight on the higher catalytic activity of the mixed-metal MIL-101(Cr/Fe) respect to MIL-101(Cr), an in situ infrared spectroscopy study was undertaken to investigate the Lewis acid sites on those solids. ${ }^{41}$ Following previous works using MIL-100(Fe) $)^{42,43}$ or MIL-100(Cr) ${ }^{18,44}$ materials, the MIL101 samples under study were activated at $150{ }^{\circ} \mathrm{C}$ under vacuum for $3 \mathrm{~h}$ to remove the water molecules coordinated to the metal centers. Then, the acid strength of the resulting coordinatively unsaturated sites (CUS) of the MIL-101 solids was studied using $\mathrm{CD}_{3} \mathrm{CN}$ and $\mathrm{CO}$ as probe molecules.

In the case of $\mathrm{CD}_{3} \mathrm{CN}$ adsorption on activated MIL-101(Cr/Fe) (4:1), the characteristic $v(C N)$ and $v\left(C_{3}\right)$ bands due to the presence of $\mathrm{CD}_{3} \mathrm{CN}$ on both the CUS or physisorbed in the solid were recorded (Figure 9). The broad $v(C N)$ band with the maximum appearing at $2320 \mathrm{~cm}^{-1}$ can be assigned to the coordinated deuterated acetonitrile on the $\mathrm{Cr}^{3+}$ and/or $\mathrm{Fe}^{3+}$ Lewis sites present in the MIL-101(Cr/Fe) (4:1) solid. This $v(C N)$ wavenumber is slightly lower than that found for MIL-100(Al) $\left(2321 \mathrm{~cm}^{-1}\right)$, a fact that agrees with the polarizing power of $\mathrm{Al}^{3+}>\mathrm{Fe}^{3+}>\mathrm{Cr}^{3+} .{ }^{45}$ In the case of MIL-101(Cr/Fe) (4:1) solid an additional $v(C N)$ band at higher wavenumber $\left(2350 \mathrm{~cm}^{-1}\right)$ appeared and could be assigned to adsorption of $\mathrm{CD}_{3} \mathrm{CN}$ on metal defects with a higher Lewis acidity as it has been proposed in the case of the MIL-100(Al) $\left(\mathrm{V}(\mathrm{CN}) 2341 \mathrm{~cm}^{-1}\right) .^{45}$ Physisorbed acetonitrile is characterized by the $\mathrm{v}(\mathrm{CN})$ band appearing at lower wavenumbers $\left(2274-2261 \mathrm{~cm}^{-1}\right)$. The band corresponding to the $v\left(C_{3}\right)$ can be observed at $2112 \mathrm{~cm}^{-1}$. For comparison, $\mathrm{CD}_{3} \mathrm{CN}$ adsorption on activated $\mathrm{MIL}-101(\mathrm{Cr})$ was also studied. The higher $\mathrm{v}(\mathrm{CN})$ wavenumbers of $\mathrm{MIL}-101(\mathrm{Cr} / \mathrm{Fe})$ (4:1) $\left(2320\right.$ and $\left.2350 \mathrm{~cm}^{-1}\right)$ vs. MIL-101(Cr) $\left(2318\right.$ and $2344 \mathrm{~cm}^{-}$ ${ }^{1}$ ) is an indication of the stronger Lewis acidity of the former. Again, this observation agrees with the charge to radius ratio of the $\mathrm{Cr}^{3+}$ vs. $\mathrm{Fe}^{3+}$ and, then, with the expected higher polarizing power of $\mathrm{Fe}^{3+}$ vs. $\mathrm{Cr}^{3+}$ as Lewis center. ${ }^{45}$ Once the $\mathrm{CD}_{3} \mathrm{CN}$ equilibrium was reached for $\mathrm{MIL}-101(\mathrm{Cr} / \mathrm{Fe})$, outgassing the samples led to a decrease of the area under the peak at $2350 \mathrm{~cm}^{-1}$ in less extent than that of $2320 \mathrm{~cm}^{-1}$. This suggests that the stronger the Lewis acidity of the metal nodes, the 


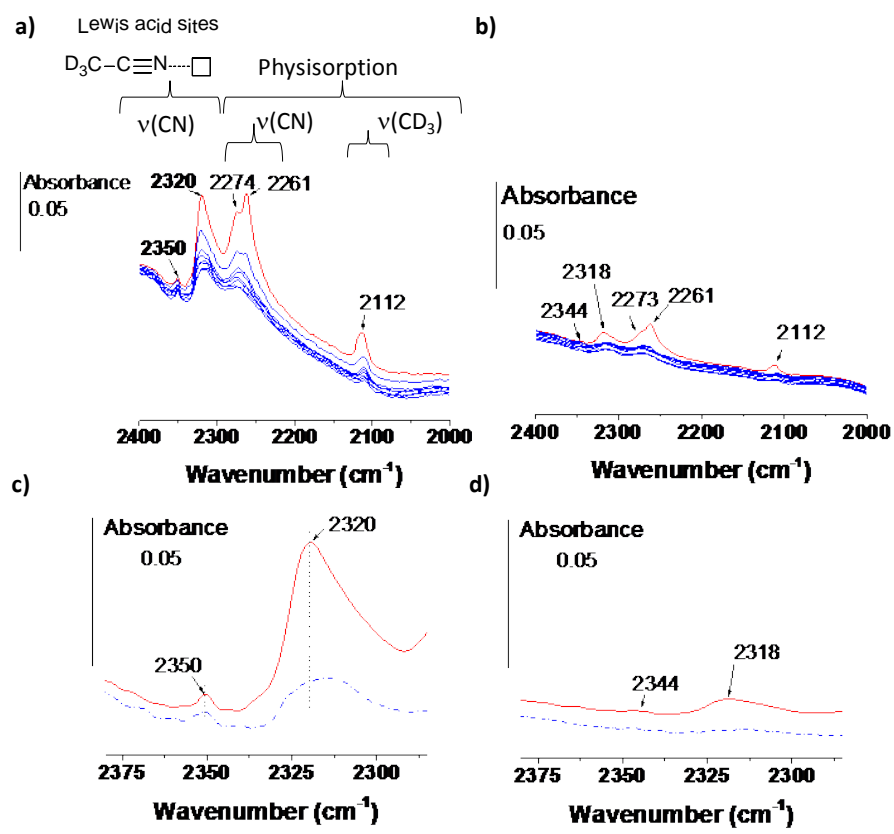

higher the observed $\mathrm{v}(\mathrm{CN})$ wavenumber and, therefore, the stronger the adsorption of the probe.

Figure 9. FT-IR spectra of $\mathrm{CD}_{3} \mathrm{CN}$ adsorbed in MIL-101(Cr/Fe) (a, c) or MIL-101(Cr) (b, d). Red line spectra show the equilibrated $\mathrm{CD}_{3} \mathrm{CN}$ adsorbed in MOFs; Blue line spectra show the retained $\mathrm{CD}_{3} \mathrm{CN}$ after outgassing the corresponding MOF for $1 \mathrm{~h}$ period.

Importantly, for the same weight of MIL-101(Cr/Fe) and MIL-101(Cr) solids the $\mathrm{CD}_{3} \mathrm{CN}$ adsorption measurements indicated a ten-fold increase of the area corresponding to the peaks at 2350 and $2320 \mathrm{~cm}^{-1}$ in MIL-101(Cr/Fe) (4:1) compared to that of MIL-101(Cr). The higher $\mathrm{v}(\mathrm{CN})$ wavenumber value and the larger peak area in the case of MIL-101(Cr/Fe) respect to MIL-101(Cr), indicates the presence of higher density and stronger Lewis acidity of the metal nodes in MIL-101(Cr/Fe) respect to MIL-101(Cr). These results are in sharp contrast with those previously reported for MIL-100(Cr) vs. MIL-100(Fe) that indicate a higher Lewis acid density for MIL-100(Cr). ${ }^{45}$ This might be a consequence of the partial poisoning of the strongest Lewis sites in MIL-100(Fe) and/or the presence of structural defects in MIL-100(Cr). In any case, it seems that for the mixed metal $\mathrm{Cr} / \mathrm{Fe}$ solid, the presence of the two metals is associated with a higher density of structural defects characterized by the $2350 \mathrm{~cm}^{-1} \mathrm{v}(\mathrm{CN})$ band and stronger CUS Lewis sites corresponding to the $2320 \mathrm{~cm}^{-1} \mathrm{v}(\mathrm{CN})$ band.

The acidity of the MIL-101(Cr/Fe) (4:1) material was further characterized by IR spectroscopy by using $\mathrm{CO}$ as probe molecule. Figure $\mathrm{SI}-12$ shows three main $\mathrm{v}(\mathrm{CO})$ bands corresponding to $\mathrm{CO}$ coordinated with Lewis acid sites $[\mathrm{v}(\mathrm{CO})$ at $2195 \mathrm{~cm}^{-1}$ ], CO interacting with Brönsted acid sites [ $\mathrm{v}(\mathrm{CO})$ at $2161 \mathrm{~cm}^{-1}$ ] and physisorbed species [ $\mathrm{v}(\mathrm{CO})$ at $\left.2136 \mathrm{~cm}^{-1}\right]$. In the case of MIL-101(Cr), similar CO bands were also observed although slightly shifted to lower wavenumber values for the Lewis and Brönsted acid sites respect to the mixed-metal MIL-101(Cr/Fe) (4:1). These observations are in agreement with the higher acidity of the MIL-101(Cr/Fe) (4:1) solid in respect to MIL-101(Cr) observed using $\mathrm{CD}_{3} \mathrm{CN}$ as probe. Once the $\mathrm{CO}$ equilibrium was achieved in each MIL-101 sample, a vacuum treatment slightly decreased the peak intensity of the Lewis centers, while the signals of the weaker Brönsted acid sites as well as those of physisorbed $\mathrm{CO}$ species were almost completely vanished.

This IR spectroscopy study allowed us concluding that the higher catalytic activity observed for MIL-101(Cr/Fe) arises mainly from the increase of Lewis acidity due to the incorporation of Fe ions at the metal nodes. In agreement with this conclusion, when the Prins reaction was carried out using the MIL-101(Cr/Fe) (4:1) solid adding pyridine as a base, ${ }^{46}$ the resulting catalytic activity was drastically reduced (Figure $\mathrm{SI}-13$ in supporting information).

\section{Conclusions}

The present study illustrates the advantages of combining the structural robustness and porosity, characteristic of MIL$101(\mathrm{Cr})$ material with the presence of $\mathrm{Fe}^{3+}$ as active Lewis sites. Overall, the present study exemplifies the potential that mixed-metal MOF offer in catalysis, particularly when preparation methods make possible to prepare crystalline materials with a wide range of metal proportions as it is the case of the present MIL-101 materials.

\section{Experimental section}

\section{Materials}

All the reagents and solvents employed in this work were of analytical or HPLC grade and supplied by Sigma-Aldrich.

\section{Catalyst preparation}

MIL-101(Cr), ${ }^{10,12} \mathrm{MIL}-101(\mathrm{Fe})^{14}$ and MIL-88B(Fe) $)^{47}$ have been prepared as previously reported. MIL-101(Cr/Fe) materials were prepared by mixing $1.5 \mathrm{mmol}$ terephthalic acid, $1 \mathrm{mmol}$ metal source $(\mathrm{Cr}$ and $\mathrm{Fe})$ and $10 \mathrm{~mL}$ tetramethylammonium hydroxide (TMAOH) solution $(0.06 \mathrm{M})$ in a Teflon reactor. More precisely, $0.75 \mathrm{mmol} \mathrm{Cr}\left(\mathrm{NO}_{3}\right)_{3} \cdot 9 \mathrm{H}_{2} \mathrm{O}$ and $0.25 \mathrm{mmol}$ of $\mathrm{Fe}^{0}$ were used for MIL-101(Cr/Fe) $(4: 1)$ and $0.85 \mathrm{mmol}$ $\mathrm{Cr}\left(\mathrm{NO}_{3}\right)_{3} \cdot 9 \mathrm{H}_{2} \mathrm{O}$ and $0.15 \mathrm{mmol}$ of $\mathrm{Fe}^{0}$ for $\mathrm{MIL}-101(\mathrm{Cr} / \mathrm{Fe})$ (5.9:1). The reaction mixtures were heated at $150{ }^{\circ} \mathrm{C}$ for $48 \mathrm{~h}$ under autogenous pressure. The obtained solids were isolated by centrifugation ( $20 \mathrm{~min}, 14500 \mathrm{rpm}$ ) and washed three times with water and three times with abs. EtOH. Density separation was performed to remove any iron oxide impurities from the MOFs. In order to remove the residual ligand molecules from the pores, the solids were treated with a solution of KF (0.1 M) for $1 \mathrm{~h}$. The purified products were dried at $100{ }^{\circ} \mathrm{C}$ overnight, prior to their characterization.

\section{Characterization}


Powder X-ray diffraction patterns were obtained on a Siemens D5000 diffractometer using $\mathrm{Cu} \mathrm{K}_{\alpha} 1,2$ radiation $(\lambda=1.5406 \AA)$.

$\mathrm{N}_{2}$ sorption measurements were performed at $77 \mathrm{~K}$ on a BELL Japan Belsorp Max apparatus, after an overnight activation of the samples at $150{ }^{\circ} \mathrm{C}$, under primary vacuum.

${ }^{57} \mathrm{Fe}$ Mössbauer spectra were recorded at 300 and $77 \mathrm{~K}$ using a

${ }^{57} \mathrm{Co} / \mathrm{Rh}$ y-ray source moving with a triangular velocity form and mounted on a conventional electromagnetic drive. The hyperfine structure was modeled by a least-square fitting procedure involving quadrupolar doublets composed of Lorentzian lines. The isomer shift values (IS) are referred to $\alpha$ Fe at $300 \mathrm{~K}$, while the samples consist of a thin layer of powder containing about $15 \mathrm{mg}$ of Fe.

The metal content ( $\mathrm{Cr}$ or $\mathrm{Fe}$ ) of the MOF samples was determined by using inductively coupled plasma optical emission spectroscopy (ICP-OES, Perkin-Elmer). Previously to ICP-OES analysis, the solid samples $(10 \mathrm{mg})$ were digested using concentrated $\mathrm{HNO}_{3}\left(65 \mathrm{wt} \% ; 20 \mathrm{~mL}\right.$ ) at $80{ }^{\circ} \mathrm{C}$ for $24 \mathrm{~h}$. The resulting solution was diluted with Milli-Q water and, then, analyzed by ICP-OES.

FTIR spectroscopy was performed by compression the solid samples at 2 Ton in air prior to recording the spectra. In some cases the sample was mixed with $\mathrm{SiO}_{2}$ as binder. Then, the samples were placed in a quartz cell equipped with KRs-5 (thallium bromoiodide) windows. The cell was connected to a vacuum line for activation ( $\mathrm{P}_{\text {residual }}=10^{-5} \mathrm{mbar}$ for $2 \mathrm{~h}$ ) prior to $\mathrm{CO}$ or $\mathrm{CD}_{3} \mathrm{CN}$ adsorption. For the $\mathrm{CO}$ adsorption experiments, the temperature of the pellet was decreased to about $-170{ }^{\circ} \mathrm{C}$ by cooling the sample holder with liquid $\mathrm{N}_{2} \cdot \mathrm{CD}_{3} \mathrm{CN}$ adsorption experiments have been carried out at room temperature. The addition of $\mathrm{CO}$ in the cell was from 0 to $2.56 \mathrm{mbar}$, approximately. $\mathrm{CD}_{3} \mathrm{CN}$ adsorption was performed at 0.26 or 0.82/0.35 mbar for MIL-101(Cr/Fe) or MIL-101(Cr), respectively. Transmission IR spectra were recorded in the $4000-400 \mathrm{~cm}^{-1}$ range, at $4 \mathrm{~cm}^{-1}$ resolution, on a VERTEX 70 spectrophotometer equipped with DTGS (Deuterated triglycine sulfate detector).

\section{Catalytic reactions}

Prins reaction. Prior to its use as catalyst, the corresponding amount of the solid (typically $0.02 \mathrm{mmol}$ of $\mathrm{Cr}+\mathrm{Fe}$ metal) was dried in a two-necked round bottom flask $(25 \mathrm{~mL})$ at $100{ }^{\circ} \mathrm{C}$ for $12 \mathrm{~h}$. Then, the system was heated at $150{ }^{\circ} \mathrm{C}$ under vacuum for $16 \mathrm{~h}$. Subsequently, the system was cool down to $80{ }^{\circ} \mathrm{C}$ and the reagents added to the system under continuous magnetic stirring in the following order: acetonitrile $(1.26 \mathrm{~mL})$, formaldehyde $(750 \mu \mathrm{L}, 5 \mathrm{mmol})$ and $\beta$-pinene $(800 \mu \mathrm{L}, 5$ $\mathrm{mmol})$.

Selective quenching experiments were carried out as described above, but adding pyridine at $20 \mathrm{~mol} \%$ respect to the substrate.

Reuse experiments were carried out under the general reaction conditions. At the end of each run, the catalyst was recovered by filtration through a Nylon membrane $(0.2 \mu \mathrm{m})$. The retained solid was washed by flushing hot acetonitrile (50 ${ }^{\circ} \mathrm{C}, 400 \mathrm{~mL}$ ) and, then, ethanol $\left(20{ }^{\circ} \mathrm{C}, 600 \mathrm{~mL}\right)$. The resulting solid was dried in an oven at $100{ }^{\circ} \mathrm{C}$ for at least $12 \mathrm{~h}$ before being employed in a subsequent catalytic cycle.

The progress of the reaction was followed by gas chromatography (GC) using a flame ionization detector (FID). During the reaction several aliquots $(100 \mu \mathrm{L})$ were sampled, then diluted with acetonitrile $(0.5 \mathrm{~mL})$ and filtered using syringe filters ( $0.2 \mu \mathrm{m}$ Nylon). Nitrobenzene was finally added as external standard (10 $\mu \mathrm{L})$ to each reaction aliquot. Quantification was carried out using a calibration plot for each commercially available compound. The samples were analyzed immediately after being taken from the reaction mixture.

\section{Conflicts of interest}

There are no conflicts to declare

\section{Author contribution}

Materials were synthesized by Effrosyni Gkaniatsou, Mónica Giménez-Marqués, Nathalie Steunou and Clémence Sicard. Catalytic experiments were initially performed by Andrea Santiago-Portillo and finalized by Cristina Vallés-García under the supervision of Sergio Navalón and Mercedes Álvaro. Mossbauer spectra were recorded and interpreted by JeanMarc Greneche. The work was conceived by Clémence Sicard, Sergio Navalón, Christian Serre and Hermenegildo García.

\section{Acknowledgements}

Financial support by the Spanish Ministry of Economy and Competitiveness (Severo Ochoa, CTQ2018-890237-CO2-R1) is gratefully acknowledged. Generalidad Valenciana is also thanked for funding (Prometeo 2017/083). Acknowledgments S.N. thanks financial support by the Ministerio de Ciencia, Innovación y Universidades (RTI 2018-099482-A-I00 project), Fundación Ramón Areces (XVIII Concurso Nacional para la Adjudicación de Ayudas a la Investigación en Ciencias de la Vida y de la Materia, 2016), and Generalitat Valenciana grupos de investigación consolidables 2019 (ref: AICO/2019/214) project. E.G thanks the ANR-11-LABEX-0039 (LabEx CHARM3AT) for financial support. M.G.-M thanks support from "la Caixa" Foundation (LCF/BO/PI19/11690022) and Generalitat Valenciana (SEJI/2020/036).

\section{Notes and references}

1. A. H. Chughtai, N. Ahmad, H. A. Younus, A. Laypkov and F. Verpoort, Chem. Soc. Rev., 2015, 44, 6804-6849.

2. A. Corma, H. Garcia and F. X. Llabrés i Xamena, Chem. Rev., 2010, 110, 4606-4655.

3. H. Furukawa, Cordova, K.E., O'Keeffe, M., Yaghi, O.M., Science, 2013, 341, 1230444.

4. J. Gascon, A. Corma, F. Kapteijn and F. X. Llabrés i Xamena, ACS Catal., 2014, 4, 361-378. 
5. M. Yoon, R. Srirambalaji and K. Kim, Chem. Rev., 2012, 112 1196-1231.

6. A. Dhakshinamoorthy, Opanasenko, M., Čejka, J., Garcia, H., Catal. Sci. Technol., 2013, 3, 2509-2540.

7. Z. Hu and D. Zhao, CrystEngComm, 2017, 19, 4066-4081.

8. M. Opanasenko, A. Dhakshinamoorthy, Y. K. Hwang, J.-S. Chang, H. Garcia and J. Cejka, ChemSusChem 2013, 6, 865 - 871.

9. G. Ferey, C. Mellot-Draznieks, C. Serre, F. Millange, J. Dutour, S. Surble and I. Margiolaki, Science, 2005, 309, 2040-2042.

10. A. Santiago-Portillo, S. Navalón, P. Concepción, M. Álvaro and H. García, ChemCatChem, 2017, 9, 2506-2511

11. A. Dhakshinamoorthy, M. Alvaro and H. Garcia, Catal. Sci. Technol., 2011, 1, 856-867.

12. A. Santiago-Portillo, J. F. Blandez, S. Navalón, M. Álvaro and H. García, Catal. Sci. Technol., 2017, 7, 1351-1362.

13. A. Dhakshinamoorthy, A. M. Asiri and H. Garcia, Chem. Eur. J., 2016, 22, 8012-8024.

14. A. Santiago-Portillo, S. Navalon, F. Cirujano, F. Llabrés i Xamena, M. Alvaro and H. Garcia, ACS Catal., 2015, 5, 32163224.

15. P. L. Llewellyn, S. Bourrelly, C. Serre, A. Vimont, M. Daturi, L. Hamon, G. D. Weireld, J.-S. Chang, D.-Y. Hong, Y. K. Hwang, S. H. Jhung and G. Férey, Langmuir, 2008, 24, 7245-7250.

16. D.-Y. Y. K. H. Hong, Serre,C. Férey, G. Chang, J.-S. , Adv. Funct. Mater., 2009, 19, 1537-1552.

17. P. C. Horcajada, H. Heurtaux, D. Benyettou, F. Salles, F. Devic, T. Garcia-Marquez, A. Yu, C. Lavrard, H. Dutson, C.L. Magnier, E. Maurin, G. Elkaïm, E. Serre, C., Chem. Commun., 2014, 50, 68726874.

18. A. Vimont, J.-M. Goupil, J.-C. Lavalley, M. Daturi, S. Surblé, C. Serre, F. Millange, G. Férey and N. Audebrand, J. Am. Chem. Soc., 2006, 128, 3218-3227.

19. J. H. Wang, Y. Zhang, M. Li, S. Yan, D. Li and X. M. Zhang, Angew. Chem. Int. Ed., 2016, 56, 6478-6482.

20. S. Abednatanzi, P. G. Derakhshandeh, H. Depau, F.-X. Coudert, P. Van Der Voort and K. Leus, Chem. Soc. Rev., 2019, 48, 2535-2565.

21. M. Giménez-Marqués, A. Santiago-Portillo, S. Navalón, M. Álvaro, V. Briois, F. Nouar, H. Garcia and C. Serre, J. Mater. Chem. A., 2019, 7, 20285-20292.

22. M. Y. Masoomi, A. Morsali, A. Dhakshinamoorthy and $\mathrm{H}$. Garcia, Angew. Chem. Int. Ed., 2019, 58, 15188-15205.

23. F. Nouar, T. Devic, H. Chevreau, N. Guillou, E. Gibson, G. Clet, M. Daturi, A. Vimont, J. M. Grenèche, M. I. Breeze, R. I. Walton, P. L. Llewellyne and C. Serre, Chem. Commun., 2012, 48, 10237 10239

24. T. A. Vu, G. H. Le, C. D. Dao, L. Q. Dang, K. T. Nguyen, P. T. Dang, H. T. K. Tran, Q. T. Duong, T. V. Nguyen and G. D. Lee, RSC Adv, 2014, 4, 41185-41194.

25. T. Tanasaro, K. Adpakpang, S. Ittisanronnachai, K. Faungnawakij, T. Butburee, S. Wannapaiboon, M. Ogawa and S. Bureekaew, Cryst. Growth Des., 2018, 18, 16-21.

26. S. Surblé, C. Serre, C. Mellot-Draznieks, F. Millange and G. Férey, Chem. Commun., 2006, 284-286.

27. C. Serre, F. Millange, C. Thouvenot, M. Noguès, G. Marsolier, D. Louër and G. Férey, J. Am. Chem. Soc., 2002, 124, 1351913526.
28. E. Stavitski, M. Goesten, J. Juan-AlcaÇiz, A. Martinez-Joaristi, P. Serra-Crespo, A. V. Petukhov, J. Gascon and F. Kapteijn, Angew. Chem. Int. Ed., 2011, 50, 9624 -9628.

29. C. Castillo-Blas, N. Snejko, V. A. de la Peña-O'Shea, J. Gallardo, E. Gutiérrez-Puebla, M. A. Monge and F. Gándara, Dalton Trans., 2016, 45, 4327-4337.

30. P. B. S. Rallapalli, M. C. Raj, S. Senthilkumar, R. S. Somani and H. C. Bajaja, Environ. Prog. Sustain. Energ., 2016, 35, 461-468.

31. M. H. Wickenheisser, A.; Tannert, R.; Milow, B.; Janiak, C. , Micropor. Mesopor. Mat., 2015, 215, 143-153.

32. J. Z. Yang, Q.; Li, J.; Dong, J., Micropor. Mesopor. Mat., 2010, 130, 174-179.

33. B. G. Abeykoon, J.-M.; Jeanneau, E.; Chernyshov, D.; Goutaudier, C.; Demessence, A.; Devic, T.; and A. Fateeva, Dalton Trans. T, 2017, 46, 517-523.

34. G. M. Férey, F.; Morcrette, M.; Serre, C.; Doublet, M.-L.; Grenèche, J.-M.; Tarascon, J.-M, Angew. Chem. Int. Ed., 2007, 46, 3259-3263.

35. P. S. Horcajada, S.; Serre, C.; Hong, D.-Y.; Seo, Y.-K.; Chang, J.S.; Grenèche, J.-M.; Margiolaki, I.; and G. Férey, Chem Commun 2007, 27, 2820-2822.

36. F. G. Delolo, K. C. B. Oliveira, E. N. dos Santos and G. E.V., Mol. Catal., 2019, 462, 1-9.

37. S. J. Rogge, A. Bavykina, J. Hajek, H. Garcia, A. I. OlivosSuarez, A. Sepúlveda-Escribano, A. Vimont, G. Clet, P. Bazin, F. Kapteijn, M. Daturi, E. V. Ramos-Fernandez, F. X. Llabrés i Xamena, V. Van Speybroeck and J. Gascon, Chem. Soc. Rev., 2017, 46, 3134-3184.

38. I. Y. Skobelev, K. A. Kovalenko, V. P. Fedin, A. B. Sorokin and O. A. Kholdeeva, Kinet. Catal., 2013, 54, 607-614.

39. I. Y. Skobelev, A. B. Sorokin, K. A. Kovalenko, V. P. Fedin and O. A. Kholdeeva, J. Catal., 2013, 298, 61-69.

40. A. Gómez-Paricio, A. Santiago-Portillo, S. Navalón, P. Concepción, M. Alvaro and H. Garcia, Green Chem., 2016, 508515.

41. A. Vimont, F. Thibault-Starzyk and M. Datur, Chem. Soc. Rev., 2010, 39, 4928-4950.

42. A. Dhakshinamoorthy, M. Alvaro, P. Horcajada, E. Gibson, M. Vishnuvarthan, A. Vimont, J.-M. Grenèche, C. Serre, M. Daturi and H. Garcia, ACS Catal., 2012, 2, 2060-2065.

43. H. Leclerc, A. Vimont, J.-C. Lavalley, M. Daturi, A. D. Wiersum, P. L. Llwellyn, P. Horcajada, G. Férey and C. Serre, Phys. Chem. Chem. Phys., 2011, 13, 11748-11756.

44. J. W. Yoon, H. Chang, S.-J. Lee, Y. K. Hwang, D.-Y. Hong, S.-K. Lee, J. S. Lee, S. Jang, T.-U. Yoon, K. Kwac, Y. Jung, R. S. Pillai, F. Faucher, A. Vimont, M. Daturi, G. Férey, C. Serre, G. Maurin, Y.-S. Bae and J.-S. Chang, Nat. Mater., 2017, 16, 526-531.

45. C. Volkringer, H. Leclerc, J.-C. Lavalley, T. Loiseau, G. Férey, M. Daturi and A. Vimont, J. Phys. Chem. C, 2012, 116, 5710-5719.

46. T. Barzetti, E. Selli, D. Moscotti and L. Forni, J. Chem. Soc. Fararday Trans., 1996, 92, 1401-1407

47. P. Horcajada, F. Salles, S. Wuttke, T. Devic, D. Heurtaux, G. Maurin, A. Vimont, M. Daturi, O. David, E. Magnier, N. Stock, Y. Filinchuk, D. Popov, C. Riekel, G. Férey and C. Serre, J. Am. Chem. Soc., 2011, 44, 17839-17847. 
